form to prepare the reader for its use in solid-state theory.

A detailed quantitative discussion of ionic and covalent binding precedes the chapter on crystals and the metallic state. Lithium is taken as a typical metal, and the reason for its metallic properties deduced from its $2 s$ wave-function. Next, a onedimensional square-well model of a metal is considered, and compared with a wave-filter for which $V$ is the analogue of $\Psi^{*}$. It is pointed out that matters are much more complicated with actual potential distributions in three dimensions (Brillouin zones are mentioned but not discussed) but that the general principles are the same. Three chapters on the mechanical, thermal and electrical properties of solids follow ; and these properties are explained in terms of quantum mechanics. Semiconductors and their many applications are treated fully, and the final chapters deal with thermionic emission, electron optics, radioactivity, and nuclear reactions.

The book is satisfying because the author does not attempt to oversimplify a difficult argument, but instead precedes it by taking simpler cases which allow of a naturally straightforward treatment and analysing them thoroughly. The mathematics is kept to a level that does not require the specialist techniques of the mathematical physicist. For example, the Fermi distribution is introduced with the statement that a Maxwell distribution for conduction electrons could not satisfy the exclusion principle, and this one does; the formula for the Fermi distribution is stated without proof, but its meaning and some of its consequences are explained and worked out quantitatively in the fullest detail.

Many numerical exercises are included, and at the end of each chapter there are references to standard treatises; the reader who has worked through this book should certainly be well equipped to consult such more specialized works with understanding.

G. R. NOAKES

\section{DISEASES OF TOBACCO IN AFRICA}

Tobacco Diseases, with special reference to Africa By Dr. J. C. F. Hopkins. Pp. xvi $+178+4$ plates. (Kew : Commonwealth Mycological Institute, 1956.) $35 s$.

THIS book is one of a series published by the Commonwealth Agricultural Bureaux on diseases of tropical and subtropical plants. Dr. S. P. Wiltshire says in his foreword that it is designed for plant pathologists, extension officers and tobacco farmers.

The first part of the book is devoted to a detailed consideration of the problems involved in the production of disease-free tobacco seedlings and the maintenance of healthy plants from transplanting to reaping. The subjects discussed include the preparation of seed-beds, cleaning and disinfecting seed, spraying both in the seed-beds and in the field, and the effects of some cultural practices on disease control. The main points of all these operations are dealt with fairly comprehensively, though some of the recommendations will be questioned by the more progressive growers and by many of those engaged in tobacco research in Rhodesia to-day. Some examples of these might include the use of bricks and cheese cloth in seed-beds, the advice to remove and burn or compost all tobaceo stalks in preference to ploughing them in, and priming (removal of lower leaves) as a method of disease control.

The second part of the book contains detailed descriptions of symptoms of diseases and disorders which may be encountered by tobacco growers. Following the pattern of his earlier handbook, "Diseases of Tobacco in Southern Rhodesia", the author introduces each description with a few notes on the causal organism. There are many excellent photographs and coloured plates showing symptoms of the diseases which are described in the text, and these should prove useful to students of tobacco culture, extension officers and farmers. The descriptions include some bacterial, fungal and virus diseases which are comparatively rare, as well as those which are more common. There are also sections dealing with physiological, deficiency and miscellaneous diseases and those peculiar to the curing barn.

Some of the control measures advocated do not find support in the data and recommendations published by the Tobacco Research Board of Rhodesia and Nyasaland in recent years. To that extent this book will tend to confuse rather than to clarify the thoughts of farmers on the control of diseases in tobacco. Nevertheless, this book brings together the author's experiences and personal observations of tobacco disease problems in the course of a long career in Africa, and will therefore be read with great interest by those working with this crop.

\section{NEAS}

\section{BIOLOGY OF SENESCENCE}

\section{The Biology of Senescence}

By Dr. Alex Comfort. Pp. xiii +257. (London: Routledge and Kegan Paul, Ltd., 1956.) 25s. net.

$\mathrm{D}$ R. COMFORT has made sure that there are no misconceptions about the subject of his book by calling it the "Biology of Senescence" rather than "The Biology of Ageing". He goes still further in precision by defining what he means by senescence. It is, he says, an increasing likelihood of death with increasing age, or "a decrease in viability and an increase in vulnerability". This precision has much to support it, and in fact one might say that the advance of gerontological studies is to some extent dependent upon the use of a scientifically accurate nomenclature. The word 'ageing', which is often used synonymously with 'senescence', has a very much wider connotation and could include all the changes in the individual following conception and until death.

In his book Dr. Comfort first provides an introduction and historical discussion. In this he devotes some space to that remarkable sponsor of the term 'biological time', Lecomte du Noüy, who in 1936 devoted a good deal of thought to a discussion of the significance of physiological and physical time: "Everything, therefore, occurs as if sidereal time flowed four times fastor for a man of fifty than for a child of ten" and "a year ... seems longer to a child" ... . "Thus we find that when we take physiological time as a unit of comparison physical time no longer flows uniformly". Dr. Comfort takes a cue from these metaphysical circumlocutions and adds to this system "alcoholic time", which he defines as the apparent progress of a bottle towards emptiness as it appears to the alcoholic who 